East African Medical Journal Vol. 79 No. 11 November 2002

EFFECT OF MICRONUTRIENT FORTIFIED BEVERAGE ON NUTRITIONAL ANAEMIA DURING PREGNANCY

S.R. Tatala, MD, Department of Food Science and Nutrition, Tanzania Food and Nutrition Centre, P.O. Box 977, Dar es Salaam, Tanzania, D. Ash, PhD, Department of Nutrition, Havard School of Public Health, Boston MA, USA, D. Makola, MD, M. Latham. PhD, Department of Nutritional Sciences. Cornell University, Ithaca NY, USA, G. Ndossi, PhD, Department of Food Science and Nutrition, Tanzania Food and Nutrition Centre, P.O. Box 977, Dar es Salaam, Tanzania, and Y. Grohn, PhD, Department of Nutritional Sciences, Cornell University, Ithaca NY, USA

Request for reprints to: Dr. S.R. Tatala, Department of Food Science and Nutrition, Tanzania Food and Nutrition Centre, Ocean Road 22, P.O. Box 977, Dar es Salaam. Tanzania

\title{
EFFECT OF MICRONUTRIENT FORTIFIED BEVERAGE ON NUTRITIONAL ANAEMIA DURING PREGNANCY
}

\author{
S.R. TATALA, D. ASH, D. MAKOLA, M. LATHAM, G. NDOSI and Y. GROHN
}

\begin{abstract}
Objective: To evaluate the efficacy of a multiple micronutrient fortified beverage containing eleven nutrients at physiological levels in prevention of anaemia and improving iron and vitamin $A$ status during pregnancy.

Design: A randomised double blind placebo controlled study.

Setting: Mpwapwa and Kongwa Districts in Dodoma Region of Tanzania.

Subjects: Five hundred and seventy nine pregnant women were screened for entry into the study and 439 women who met the study criteria were enrolled.

Interventions: Study participants received either a fortified (F) or non-fortified (NF) orange flavoured drinks identical in appearance, provided in two self administered servings per day for an eight week period.

Main outcome measures: Comparison of haemoglobin $(\mathrm{Hb})$, serum ferritin (SF) and serum retinol (SR) at baseline and follow up.

Results: After eight weeks of supplementation, the $F$ group $(n=129)$ had a significantly higher Hb increase of $0.86 \mathrm{~g} / \mathrm{dL}$ compared to $0.45 \mathrm{~g} / \mathrm{dL}$ in the NF group $(n=130) p<0.0001$. Gestational age at entry into the study, moderated the effect on $\mathrm{Hb}$ of the fortified drink. Women at earlier gestational age upon entry, had a higher rise in $\mathrm{Hb}$ than women of late gestational age $(0.8 \mathrm{~g} / \mathrm{dL}$ versus $0.04 \mathrm{~g} / \mathrm{dL}$ rise respectively, $\mathrm{p}=0.038, \mathrm{n}=188)$. The risk of being anaemic at the end of the study for those in the $F$ group was reduced by $51 \%(\mathrm{RR}=0.49, \mathrm{CI}=0.28$ to 0.85 ). Iron stores (by serum ferritin levels) increased by $3 \mu \mathrm{g} / \mathrm{L}$ in the $F$ group $(p=0.012)$ and a decrease of $2 \mu \mathrm{g} / \mathrm{L}$ in the NF group ( $p=0.115$ ). The follow up ferritin concentration depended on initial ferritin level. Regardless of treatment group, serum retinol concentrations were significantly higher in mothers who had delivered. Mothers who had adequate levels at entry benefited more from the supplement than those with low levels $(0.26 \mu \mathrm{mol} / \mathrm{L}$ versus no significant difference). Conclusions: The multiple micronutrient-fortified beverage given for eight weeks to pregnant women improved their haemoglobin, serum ferritin and retinol status. The risk for anaemia was also significantly reduced. The important predictors of $\mathrm{Hb}$ increase at follow up were the fortified beverage, baseline $\mathrm{Hb}$, serum retinol, baseline ferritin and gestational age at entry into study. Anthropological research showed that the beverage was highly acceptable and well liked.
\end{abstract}

\section{INTRODUCTION}

The World Health Organisation (WHO) estimates that $35 \%$ to $75 \%$ of pregnant women in developing countries and $18 \%$ of women from industrialised countries become anaemic during pregnancy(1). In Tanzania, the prevalence of anaemia lies between $36 \%$ to over $75 \%$ of pregnant women, and it is shown to vary with altitude, being very prevalent along the coastal belt(2-5).

The common cause of nutritional anaemia is iron deficiency, although there is evidence to suggest that deficiencies of B12, folate, vitamin A and zinc contribute either singly or in combination to maternal anaemia(68). Furthermore dependence on cereal and legume based diets, which often lack animal protein as well as fruits and vegetables that enhance absorption of nonhaem iron aggravate the condition. Increased iron requirements during pregnancy, and prevalence of parasitic infections such as hookworm and schistosomiasis further predisposes to severe anaemia in the poor countries. Malaria also contributes to anaemia in childbearing women. As a result maternal mortality and adverse pregnancy outcomes such as 
foetal loss, prematurity and low birth weight are increased $(9,10)$. This calls for correction of pregnancy induced iron deficiency anaemia otherwise women will suffer the described consequences.

In Tanzania prophylaxis against nutritional anaemia have focussed on mainly combating iron deficiency anaemia. Use of iron supplements as recommended by the WHO guidelines(11) has been implemented throughout the country. Iron tablets are distributed free of charge in government clinics that provide antenatal care. Despite this measure the prevalence of anaemia during pregnancy has remained high due to low compliance, logistic problems and inadequate knowledge of primary health worker on how to instruct women on use of haematinics(12-14). Since women with anaemia during pregnancy also suffer multiple nutritional deficiencies, the use of multiple micronutrient supplements is being advocated as an alternative measure(15-17). The objective of this study was to evaluate the efficacy of one such multiple micronutrientfortified beverage in improving haemoglobin level in two rural districts of central Tanzania.

\section{MATERIALS AND METHODS}

The study was conducted between the months of August and December 1999 in study subjects predominantly the Wagogo and Wakaguru of Mpwapwa and Kongwa Districts of Dodoma Region, Tanzania. The area is semi-arid and agricultural production is usually seasonal.

The study subjects were mothers of gestational age between 10 and 34 weeks. A maximum gestational age of 34 weeks was chosen to ensure that mothers had at least eight weeks of supplementation before delivery. Eligibility criteria included $\mathrm{Hb}$ greater than or equal to $8.0 \mathrm{~g} / \mathrm{dL}$ and absence of a serious medical disorder during the current pregnancy. Out of 579 pregnant women who were screened for enrolment, only 439 met the study criteria.

The study was approved by the Research and Ethics Committee of the Tanzania Food and Nutrition Centre, as well as by Cornell University Committee on human Subjects. Informed consent was obtained from the study participants.

The study design was a double blind placebo controlled trial with two groups. Sample size was calculated using a haemoglobin difference of $0.8 \mathrm{~g} / \mathrm{dL}$, with a power of $80 \%$ and a confidence level of $95 \%$. After adjusting for a $25 \%$ potential drop out rate each of the two groups required 211 participants. At each of the study centres a block randomisation (ten subjects in each block) was used to assign the pregnant women to one of the two study groups i.e., receiving fortified beverage ( $\mathrm{F}$ group) and receiving non-fortified beverage ( $\mathrm{NF}$ group).

The micronutrient fortified beverage produced by food technologists at the Procter \& Gamble Company, contained eleven nutrients. Most of the doses of micronutrients in the beverages were lower than recommended daily allowances for supplements during pregnancy. The nutrients include: iron, vitamin A, iodine, zinc, vitamin C, riboflavin, folic acid, vitamin Bl2, vitamin B6. Niacin and vitamin $E$, shown in Table 1 with reference to the FAO/WHO recommended levels, under results. The content of one sachet was added to $250 \mathrm{ml}$ of clean previously boiled water to produce a single serving. Each subject was asked to drink two sachets daily, one with the morning meal and another with an evening meal. The women collected their supplies fortnightly. All the empty packages were returned and counted before providing a new supply every two weeks.

Table 1

Quantities of nutrients in the fortified beverage consumed daily compared with the FAONWHO recommended daily allowances during third trimester of pregnancy

\begin{tabular}{|c|c|c|}
\hline Nutrient & $\begin{array}{c}\text { Amount } \\
\text { (2 servings) }\end{array}$ & $\begin{array}{c}\text { RDA FAO } \\
\text { WHO }^{1}\end{array}$ \\
\hline Iron (low bioavailability) ${ }^{2}(\mathrm{mg})$ & 3) 10.8 & $92-152$ \\
\hline Vitamin A $(\mu \mathrm{g}$ RE) & 1050 & 600 \\
\hline Iodine $(\mu \mathrm{g})$ & 90 & 200 \\
\hline Zinc (mg) & 10.5 & 2 \\
\hline Vitamin C (mg) & 144 & 50 \\
\hline Riboflavin (mg) & 1.2 & 1.5 \\
\hline Folic Acid $(\mu \mathrm{g})$ & 280 & $370-470$ \\
\hline Vitamin $\mathrm{B} 12(\mu \mathrm{g})$ & 6 & 1.4 \\
\hline Vitamin B6 $(\mu \mathrm{g})$ & 1400 & - \\
\hline Niacin (mg NE) & 10 & 12.6 \\
\hline Vitamin $E(\mu \mathrm{g} R E)$ & 21 & - \\
\hline
\end{tabular}

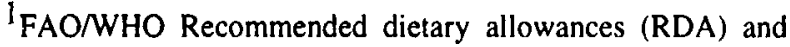
intakes for pregnant women.

${ }^{2}$ Low iron bioavailability=diet categorised as having iron absorption of about $5 \%$.

NB: The beverage had less iron content than RDA by the WHO/FAO

$\mathrm{RE}=$ Retinol equivalent, $\mathrm{TE}=(\propto-$ tocopherol equivalents, $\mathrm{NE}=$ Niacin equivalents

Laboratory measurements were taken at baseline and after eight weeks. Whole blood collected by venepuncture was used for haemoglobin determination. Haemoglobin was measured by a portable haemoglobinometer (HemoCue AB, Angelholm, Sweden). Serum ferritin (SF) was assayed via an enzyme-linked immunosorbent assay according to the method described by Flowers et. al., 1989 using commercial kits (Ramco Laboratories, Houston, Texas, USA). Accuracy was assessed using a quality control sera (Ramco Laboratories. Houston, Texas, USA and Lyphochek Immunoassay Plus Controls from Bio-rad Laboratories, Hercules, California). For all assays, samples were assayed in duplicate to measure within-run precision, and aliquots of pooled serum were used to measure inter-assay precision. Liquid Nitrogen was used to transport frozen sera from field to the laboratory for storage until analysis. Fresh urine and stool samples were collected for Schistosomiasis and hookworm ova examination. Stool preparations and urine deposits after centrifugation were examined microscopically.

Weight, height, height of the fundus and gestational age were established by a medical doctor. A questionnaire was administered to collect information on health, nutrition, morbidity and demographic factors.

Data was analysed in SPSS programme (SPSS 1999). 
Comparisons of continuous variables between groups were made using independent t-test if the variables were normally distributed. Mann-Whitney U-tests was used for non-normal data, the chi-square test were used for comparison of categorical variables including anaemia status between the two treatment groups and change in anaemia status after treatment. Before and after comparisons using normally distributed continuous data were completed using dependent t-tests. For categorical data the Sign and McNemar tests were used. Multivariate analysis was done using multiple regression for continuous dependent variables, binary logistic regression for categorical outcomes with more than two levels. One way ANOVA was used when the comparison was being made between three groups. Treatment codes were broken only after all the data analysis had been completed.

\section{RESULTS}

Of the study 579 mothers screened, 439 mothers who met the entry criteria were enrolled in the study and 259 (58.9\%) who had not delivered (129 in the fortified and 130 in the non-fortified) were included in post-intervention assessments at the eighth-week. There were no significant differences in biochemical as well as anthropometric measurements in the two groups before intervention.

Haemoglobin and ferritin changes between examination 1 and 2 :

The results in Table 2 show that used fortified beverage (F group) had a significant mean increase of haemoglobin concentration of $0.86 \pm 0.02 \mathrm{~g} / \mathrm{dL}$ and the final group mean $\mathrm{Hb}$ was $11.4 \pm 0.1 \mathrm{~g} / \mathrm{dL}$. There was also a significant increase of $0.45 \pm 0.01 \mathrm{~g} / \mathrm{dL}$ in mean $\mathrm{Hb}$ in the group given non-fortified beverage (NF group), with the mean
$\mathrm{Hb}$ at exam 2 of $10.9 \pm 0.1 \mathrm{~g} / \mathrm{dL}$. The increase in $\mathrm{Hb}$ experienced by the F-group was significantly higher than the increase experienced by the NF-group (median difference $0.42 \pm 0.01 \mathrm{~g} / \mathrm{dL}, \mathrm{p}=0.02$ ). The $\mathrm{F}$ group also experienced a significant increase of serum ferritin at follow up than the NF- group $(22.7 \pm 1.1$ versus $18.5 \pm 1.1 \mathrm{~g} / \mathrm{dL}, \mathrm{p}=0.05$ ). The mean ferritin in the $\mathrm{F}$ group at follow up was, $4.2 \mu \mathrm{g} / \mathrm{dL}$ higher than that in the $\mathrm{N}$-group $(\mathrm{p}=0.009)$. The F-group experienced a small but significant increase in ferritin of $3 \mu \mathrm{g} / \mathrm{dL}$ $(p=0.012)$ while the NF-group had a non-significant decrease of $2 \mu \mathrm{g} / \mathrm{dL}(\mathrm{p}=0.166)$.

The changes in serum retinal was less marked. However, serum retinol for those who were having normal levels before intervention increased by $0.14 \mu \mathrm{mol} /$ $\mathrm{dL}$ in the F-group and decreased by $1.2 \mu \mathrm{mol} / \mathrm{dL}$ in the $\mathrm{NF}$-group. The main difference of $0.26 \mu \mathrm{mol} / \mathrm{dL}$ was significant $(p<0.05)$.

\section{Gestational age and supplement interaction:}

The gestational age was positively associated with changes in $\mathrm{Hb}(r=0.153, p=0.036, n=188)$. The biggest increase in overall $\mathrm{Hb}$ occurred in mothers who were in the second $(0.77 \mathrm{~g} / \mathrm{dL}$ to $1.13 \mathrm{~g} / \mathrm{dL}, \mathrm{p}<0.0001)$ and third $(0.69$ to $1.06 \mathrm{~g} / \mathrm{dL}, \mathrm{p}<0.0001)$ trimester of gestational age at entry into the study. However $F$ group mothers in the first and second trimester experienced a much greater increase in $\mathrm{Hb}$ when compared to NFgroup. The difference in the increase in the third trimester was small and non-significant. A significant interaction was also found between treatment group and gestational age and was also confirmed by multivariate analysis.

Table 2

Comparison of haemoglobin, serum ferritin and retinol concentrations in mothers consuming the fortified ( $n=129)$ and non-fortified $(n=130)$ beverage after eight weeks of follow up

\begin{tabular}{|c|c|c|c|c|c|c|}
\hline \multicolumn{3}{|c|}{ Baseline and follow up measurements } & \multicolumn{3}{|c|}{ Change observed } & \multirow{3}{*}{$\begin{array}{c}\text { Group } \\
\text { t-test }(p) \\
\text { Exam } 2-1\end{array}$} \\
\hline Treatment & Exam 1 & Exam 2 & Group & Paired & Increase & \\
\hline Group & $\mathrm{X} \pm \mathrm{SEM}$ & $\mathrm{X} \pm \mathrm{SEM}$ & $\begin{array}{c}\text { t-test (p) } \\
\text { Exam } 2\end{array}$ & t-test $(p)$ & $\begin{array}{l}\text { X士SEM } \\
\text { Exam 2-1 }\end{array}$ & \\
\hline \multicolumn{7}{|c|}{ Haemoglobin(g/dL) } \\
\hline Fortified & $10.5 \pm 0.13$ & $11.4 \pm 0.12$ & 0.02 & 0.000 In & $0.86 \pm 0.08$ & 0.015 \\
\hline Non-fortified & $10.5 \pm 0.13$ & $10.9 \pm 0.13$ & $\mathrm{~F}>\mathrm{NF}$ & $0.000 \mathrm{In}$ & $0.45 \pm 0.11$ & $\mathrm{~F}>\mathrm{NF}$ \\
\hline \multicolumn{7}{|l|}{ Ferritin $(\mu \mathrm{g} / \mathrm{L})$} \\
\hline Fortified & $18.6 \pm 1.08$ & $22.7 \pm 1.07$ & 0.05 & 0.012 In & $3.04 \pm 0.02$ & 0.009 \\
\hline Non-fortified & $20.3 \pm 1.08$ & $18.5 \pm 1.08$ & $\mathrm{~F}>\mathrm{NF}$ & $0.166 \mathrm{De}$ & $-1.99 \pm 0.01$ & $\mathrm{~F}>\mathrm{NF}$ \\
\hline Fortified & $0.93 \pm 0.03$ & $1.06 \pm 0.27$ & ns & ns In & $0.13 \pm 0.01$ & 0.044 \\
\hline Non-fortified & $1.02 \pm 0.27$ & $0.96 \pm 0.28$ & $F>N F$ & ns De & $-0.06 \pm 0.01$ & $\mathrm{~F}>\mathrm{NF}$ \\
\hline
\end{tabular}

1 tail group t-test used for differences between groups at exam 2. Two tail paired t-test for non-fortified and one tail paired $t$-test for fortified group were used to test change in $\mathrm{Hb}$ between exams. De=decrease, In=increase, $\mathrm{F}>\mathrm{NF}=\mathrm{observed}$ change greater in fortified beverage (F) group than in non-fortified(NF) group, ns=not significant, SEM=standard error of mean. 


\section{Predictors of change in haemoglobin}

Table 3 shows that in the stepwise multiple regression model the important predictors of $\mathrm{Hb}$ increase, included being in the F-group, baseline $\mathrm{Hb}$, baseline serum retinol, c-reactive protein (CRP), baseline ferritin and gestational age at entry into the study. The interaction term between treatment group and gestational age was significant and negatively associated with change in $\mathrm{Hb}$. The most important predictors of $\mathrm{Hb}$ increase in order of importance were the treatment, treatment $x$ gestational age interaction, and $\mathrm{Hb}$ at entry and gestational age. According to this model the effect of treatment on change (increase) in $\mathrm{Hb}$ was modified by the gestational age of the mother at entry into study. In mothers who were about 19 weeks of gestation at entry into the study the difference was about $0.8 \mathrm{~g} / \mathrm{dL}$ and in those who were 29 weeks it was $0.04 \mathrm{~g} / \mathrm{dL}$.
Prevalence of anaemia and iron deficiency at exam 1 and 2

The prevalence of mothers with anaemia in the $\mathrm{F}(\mathrm{n}=127)$ and NF $(n=132)$ groups were $63.8 \%$ and $59.1 \%$ respectively $(p=0.438)$ at entry into the study. However at follow up, the $F$ group had a significantly lower proportion of anaemic mothers when compared to the NF-group ( $37 \%$ vs $48.5 \%, p=0.019$ ). The F-group mothers experienced a significant change in anaemia status (McNemar $\chi 2=22.674, \mathrm{n}=127, \mathrm{p}=0.000$ ) but change within the NF-group mothers was not significant. Logistic regression analysis showed that treatment had an effect on the risk of being anaemic at the end of eight weeks of supplementation. After adjusting for anaemia and vitamin A status at entry into the study mothers in the fortified group had a $51 \%$ decrease in the risk of being anaemic (Table 4).

Table 3

Predictors of post intervention change in haemoglobin stalus $(n=129)$

\begin{tabular}{lccccc}
\hline Predictor & $\beta^{1}$ & $\mathrm{SE}^{2}$ & Beta & sig. & C.I. \\
\hline Constant & 3.523 & 0.903 & - & 0.005 & $0.85-4.56$ \\
Fortified Group & 2.460 & 0.767 & 0.891 & 0.002 & $0.95-3.98$ \\
Haemoglobin at entry & -0.474 & 0.058 & -0.521 & 0.000 & $-0.59-(-0.36)$ \\
Gestational Age & 0.0863 & 0.023 & 0.355 & 0.000 & $0.04-0.13$ \\
Fortified Group & & & & & \\
Gestational age interaction & -0.0868 & 0.031 & -0.826 & 0.006 & $-0.15-(-0.03)$ \\
Serum retinol & 0.528 & 0.245 & 0.138 & 0.033 & $-0.44-1.01$ \\
Ferritin < 30 $\mathrm{Hg} / \mathrm{L}$ & -0.410 & 0.191 & -0.136 & 0.034 & $0.03-0.79$ \\
C-reactive protein & -0.143 & 0.083 & -0.114 & 0.086 & $-0.31-0.02$ \\
\hline
\end{tabular}

$R=0.601 R^{2}=0.361$ adj $R^{2}=0.334$ C. $1 .=$ Confidence Interval

$1_{\text {Regression coefficient }}$

${ }^{2} \mathrm{SE}=\mathrm{Standard}$ error of the mean

Table 4

Effect of consuming the fortified beverage on risk of anaemia and micronutrient status at the end of eight weeks of follow up

Risk factor in treatment groups

Relative Risk

95\% Confidence interval

Level of

significance

\begin{tabular}{|c|c|c|c|}
\hline \multicolumn{4}{|l|}{ Anaemia risk at follow up } \\
\hline Anaemia at entry' & 5.30 & $2.90-9.70$ & $\mathrm{p}=0.000$ \\
\hline Fortified group ${ }^{2}$ & 0.49 & $0.28-0.85$ & $\mathrm{p}=0.011$ \\
\hline Vitamin A status at entry ${ }^{3}$ & 0.37 & $0.16-0.83$ & $p=0.017$ \\
\hline \multicolumn{4}{|c|}{ Risk of iron depletion status at follow up } \\
\hline Low baseline serum ferritin ${ }^{4}$ & 0.30 & $0.09-0.76$ & $\mathrm{p}=0.05$ \\
\hline High baseline serum ferritin ${ }^{4}$ & 0.08 & $0.01-0.76$ & $p=0.05$ \\
\hline Iron deficiency anaemia & 0.44 & $0.19-1.02$ & $\mathrm{p}=0.055$ \\
\hline Iron deficiency & 4.5 & $1.95-10.6$ & $p=0.000$ \\
\hline
\end{tabular}

${ }^{1}$ Anaemia cut off used in pregnant women $=\mathrm{Hb}<11.0 \mathrm{~g} / \mathrm{dL}$

${ }^{2}$ Group supplemented with fortified beverage

${ }^{3}$ Low serum retinol $=\mathrm{SR}<0.70 \mu \mathrm{mol} / \mathrm{dL}$ (for vitamin A status)

${ }^{4}$ Low serum ferritin $=S F<30 \mu g / L$ 
Effect of supplement on iron stores at exam 2 The effect of the supplement on post-intervention ferritin or change in ferritin seemed to depend on the level of baseline ferritin. The effect of the supplement was more pronounced in those mothers who had higher ferritin levels or were iron replete at entry where it prevented significant decrease in ferritin levels. At exam 2 mothers with depleted iron stores at entry had remained iron depleted or their iron stores improved. Those with adequate iron stores had either remained iron replete or became iron depleted. The F-group mothers experienced a significant change of iron status $\left(\chi^{2}=5.63, p=0.000\right)$. There was no significant change in iron status within mothers assigned to the NF-group.

\section{Vitamin A status of anaemic pregnant women}

Serum retinol at baseline, eight weeks follow up and post partum did not differ according to treatment group. When the analysis was restricted only to mothers who had delivered at the eighth week follow up postpartum serum retinol level was significantly higher than both the baseline $(0.51 \mu \mathrm{mol} / \mathrm{dL}, \mathrm{p}=0.000)$ and the eighth week follow up $(0.71 \mu \mathrm{mol} / \mathrm{dL}, \mathrm{p}=0.000)$ levels. There was a positive correlation between follow up serum retinol and baseline serum retinol among mothers who had not delivered at follow up $(R=0.33, p=0.000$, $\mathrm{n}=242$ ).

\section{DISCUSSION}

The results from this study show that multiple micronutrient supplementation during pregnancy results in improved iron status. There was a significantly higher increase in concentration of up to $0.8 \mathrm{~g} / \mathrm{dL}$, over the eight weeks of supplementation in favour of the group that consumed the fortified beverage. After adjusting for possible confounding factors, this increase was highest in those mothers who had earlier gestational ages at entry into the study. Given the smaller doses of iron contained in the micronutrient-fortified beverage when compared to the larger doses used in most iron supplementation trials, this increase was quite reasonable. In controlled supplementation trials with larger doses of 90 to $120 \mathrm{mg}$ of iron supplements increases of between 1.2 and $1.6 \mathrm{~g} / \mathrm{dL}$ have been reported(16,22).

Since most of the micronutrients contained in the fortified beverage are essential for haemoglobin synthesis it was not possible to distinguish or separate the effects of the various micronutrients on the increase in haemoglobin. Micronutrients such as vitamin B12, folate, vitamin $A$ and iron are all essential for haemoglobin synthesis. An evaluation of the indicators of iron (serum ferritin) and vitamin A (serum retinol) status on haemoglobin change showed a positive association between baseline serum retinol and an increase in haemoglobin at the end of the study. This suggests that mothers with higher vitamin A concentrations at entry into the study were more likely to experience an increase in haemoglobin at the end of the study regardless of the treatment group they had been assigned to. According to the multivariate model a 1 unit $(\mu \mathrm{mol} / \mathrm{dL})$ increase in serum retinol will be associated with a $0.53 \mathrm{~g} / \mathrm{dL}$ in haemoglobin increase. There was no significant association between follow up vitamin $\mathrm{A}$ and change in haemoglobin, neither was there any association between change in vitamin $A$ and change in haemoglobin. The finding of a significant positive association between vitamin $A$ and haemoglobin increase is consistent with findings from iron and vitamin A supplementation trials in which a combination of iron and vitamin A resulted in a significantly higher increase in haemoglobin than when iron was given alone $(8,15,17)$.

Baseline haemoglobin was negatively associated with increase in haemoglobin. This finding is consistent with findings from other supplementation trials in which supplemented pregnant mothers with low baseline haemoglobin concentration experienced a higher increase in haemoglobin than supplemented mothers with higher haemoglobin levels(18). The beneficial effect of the micronutrient-fortified beverage on increase in haemoglobin was more pronounced in the mothers who were at earlier gestations at entry into the study. This finding reflects the pregnancy-induced increase in red blood cell formation, which tends to lead to an increase in haemoglobin during the third trimester of pregnancy $(17,18)$. Requirements for absorbed iron tend to vary with the gestational age of the pregnancy being low in the first and higher during the second and third trimester(19,21). This was also reflected in our study and the finding suggests that if physiological doses are to be used for iron supplementation then the best results will be obtained if supplementation is started earlier rather than later in pregnancy. Starting the supplementation early would ensure that the pregnant women took the supplement for a longer period of time. The women who had low ferritin (ferritin $<30 \mathrm{mg} / \mathrm{L}$ ) at entry into study had a $0.44 \mathrm{~g} / \mathrm{dL}$ lower increase in haemoglobin than those who had higher ferritin concentrations. This finding suggests that mothers with lower initial iron stores (as indicated by low ferritin levels) experienced a lesser increase in haemoglobin irrespective of the treatment group to which they have been allocated. The reduction in the risk of being iron deficient was more pronounced in those mothers who had adequate iron stores at entry into the study. After adjusting for both anaemia and vitamin A status at entry into the study, the micronutrient fortified beverage reduced the risk of being anaemic at the end of the study by $51 \%$ in mothers receiving the fortified beverage when compared to those who received the non-fortified beverage.

Both treatment groups experienced a significant increase in haemoglobin from baseline to follow up. This increase could have been due to a number of factors such as a decline in malarial infections and an 
increase in intake of foods with more bioavailable iron and other micronutrients. The study was conducted from August to December, which is just after the malarial season and soon after harvest time. During this time local farmers would still have access to their produce and would have more money for food from selling some of the produce. Studies conducted in Malawi(10) and Kenya(20) have both demonstrated that seasonal variation has an effect on anaemia and haemoglobin concentrations.

Our findings shows the benefits of this multiple micronutrient-fortified beverage on controlling anaemia during pregnancy and depending on gestational age 0.04 to $0.80 \mathrm{~g} / \mathrm{dL}$ increase in haemoglobin concentration can be achieved. However this is not a strategy to replace the regular use of haematinics but rather is an alternative in circumstances like this where compliance is a problem with the conventional method. Compliance with this beverage was good and was shown by the number of mothers who were seen at follow up with few reported complaints. This was also reported by the anthropological part of our study which showed that women asked their husbands to go and collect the supplement for them when they were unable to do so.

\section{ACKNOWLEDGEMENTS}

To the Micronutrient Initiative (MI), for financial support. UNICEF, Cornell University, Yale University, International Programme in Chemical Sciences (IPICS), and TFNC for supporting the project in different aspects and the doctors, nurses and mothers in Mpwapwa and Kongwa Districts who made this research effort a success.

\section{REFERENCES}

1. World Health Organisation. The prevalence of anaemia and in women: a tabulation of available information. Geneva, WHO. 1992.

2. Matteelli, A. Donato, F., Muchi, L.A., Leopardi, O., Astori, L. and Carosi, G. Malaria and anaemia in pregnant women in Urban Zanzibar, Tanzania. Ann. Trop. Med. Paras. 1994; 88:475-483.

3. Massawe, S.N., Urassa, E.N., Nystrom, L. and Lindmark, G. Effectiveness of primary level antenatal care in decreasing anaemia at term in Tanzania. Acta. Obstet. Gynecol. Scand. 1999; 78:573-579.

4. Bergsjo, P., Seha, A.M. and Ole-Kingori, N. Haemoglobin concentration in pregnant women. Experience from Moshi, Tanzania. Acta. Obstet. Gynecol. Scand. 1996; 75:241-244.
5. Hinderaker, S.G., Olsen, B.E., Bergsjo, P., Lie, R.T., Gasheka, P. and Kvale, G. Anaemia in pregnancy in the highlands of Tanzania. Acta. Obstet. Gynecol. Scand. 2001; 80: $18-26$.

6. Bothwell, T.H. Iron requirements in pregnancy and strategies to meet them. Amer. J. Clin. Nutr. 2000; 72(1 part 2): S257-S264.

7. Hercberg, S., Galan, P. and Dupin, H. Iron deficiency in Africa. World Rev. Nutr. Diet. 1987; 54:201-236.

8. Suharno, D., West, C.E., Karyardi, D. and Hautvast G.A.J. Supplementation with vitamin $A$ and Iron for nutritional anaemia in Pregnant women in West-Java, Indonesia. Lancet. 1993; 342:1325-1328.

9. Van den Broek, N., Eeckels, R. and Vuylsteke, J. Influence of nutritional status on child mortality in rural Zaire. Lancet. 1993; 341:1491-1495.

10. Van den Broek, N.R., Rogerson, S.I., Mhango, et al. Anaemia in pregnancy in Southern Malawi: prevalence of risk factors. Brit. J. Obstet. Gynae. 2000; 107: 445-451.

11. DeMaeyer, E.M., Dallman, P., Gurney, LM., Hallberg, L., Sood, S.K. and Srikantia, S.G., Preventing and controlling iron deficiency anaemia through primary health care: a guide to health administrators and programme managers. Geneva, Switzerland, WHO 1989; 5-58.

12. Galloway, R. and McGuire, J. Determinants of compliance with iron supplementation: supplies, side effects, or psychology? Soc. Sci. Med. 1994; 39:381-390.

13. Yip, $R$. Iron supplementation during pregnancy: Is it effective? Amer. J. Clin. Nutr. 1996; 63:853-855.

14. Ekstrom, E.C., Kavishe, F.P., Habitch, J.P. et al. Adherence to iron supplementation during pregnancy in Tanzania: Determinants and haematologic consequences. Am. J. Clin. Nutr. 1996; 64:368-374.

15. Panth, M., Shartugna, V., Yasodhara, P. and Sivakumar, B. Effect of vitamin A supplementation on haemoglobin and vitamin A levels during pregnancy. Brit. J. Nutr. 1990; 64:351-358.

16. Ladipo, O.A. Nutrition in pregnancy: mineral and vitamin supplements. Amer. J. Clin. Nutr. 2000; 72:280S-290S.

17. Chawla, P.K. and Puri, R. Impact of nutritional supplements on haematological profile of pregnant women. Indian Paediatr. 1995; 32:876-880.

18. Sood, S.K., Ramachandran, K. Mathur, M., et al. S.J. WHO sponsored collaborative studies on nutritional anaemia in India. 1. The effects of supplemental oral iron administration to pregnant women. Q. J. Med. 1975; 44:241-258.

19. Msolla, M.J. and Kinabo, J.L. Prevalence of anaemia in pregnant women during the last trimester. Int. J. Food Sc: Nutr. 1997; 48:265-270.

20. Kigutha, H.N., Van staveren, W.A.. Wijnhoven T.M.A. and Hautvast, G.A.J. Maternal Nutritional status may be stressed by seasonal flactuations in food availability-Evidence from rural women in Kenya. Int. J. Food Sc. Nutr. 1995; 46:247.255.

21. Beaton, G.H. Iron needs during pregnancy: do we need to rethink our targets? Amer. J. Clin. Nutr. 2000; 72: 265S-271S. 